\title{
EL DESARROLLO DEL VOTO DE MEXICANOS RESIDENTES EN EL EXTERIOR Y CAMBIOS AL CÓDIGO FEDERAL DE INSTITUCIONES Y PROCESOS ELECTORALES
}

\author{
Alejandro Monjaraz SANDOVal*
}

\section{RESUMEN}

Este trabajo tiene como objetivo hacer un recuento de la evolución de la ley electoral en México a partir de 1994 hasta el 2006 para permitir que los mexicanos radicados fuera del territorio nacional cuenten con la opción de ejercer su derecho constitucional de sufragio en elecciones federales. Para llegar a la actualidad electoral en México, se ha realizado un arduo trabajo de negociaciones, que involucran a la Diáspora y a las autoridades mexicanas encargadas de proteger y extender los derechos y prerrogativas de los mexicanos. Las reformas al Código, y después Legislación electoral, fueron fundamentales para que los mexicanos adopten su identidad binacional y reclamen sus derechos políticos sin importar el espacio que habiten. Como resultado de los cambios institucionales, el registro e identificación de mexicanos residentes en el exterior a través de la colaboración en materia electoral con el gobierno federal, han sido fundamentales para ampliar el alcance del aparato electoral y extender la dimensión de participación política transnacional iniciada en el último cuarto del siglo XX.

\section{Palabras clave:}

Voto extraterritorial, reforma, elecciones, relación Estado-Diáspora, COFIPE.

\section{ABSTRACT}

The purpose of this paper is to report the evolution of the electoral law in Mexico from 1994 to 2006 to allow Mexicans living outside the national territory to have the option of exercising their constitutional right to vote in federal elections.

* Universidad Autónoma de Baja California. 
To get to the electoral news in Mexico, an arduous work of negotiations has been carried out, the Diaspora and the Mexican authorities in charge of protecting and extending the rights and prerogatives of Mexicans were involved. The reforms in the Code, and then Electoral legislation, Fundamental forces for Mexicans Adopt their binational identity and Recover their rights. As a result of the institutional changes, the registration and identification of Mexicans abroad through collaboration in electoral matters with the federal government, have been essential to expand the reach of the electoral apparatus and extend the dimension of political participation transnational started in the last quarter of the twentieth century.

\section{Keywords:}

Extraterritorial vote, reform, elections, State-Diaspora relation, COFIPE.

\section{INTRODUCCIÓN}

La entrada en vigor del voto extraterritorial para los mexicanos residentes en el exterior tuvo un largo y tedioso recorrido que requirió de esfuerzos conjuntos de la sociedad y el gobierno. Parte de ello se debe a la compleja historia de la relación de México y su diáspora que se basa, primero, en las intenciones económicas y, luego, en las políticas de participación política que rebasa los límites fronterizos. Hasta hace poco tiempo, las remesas han sido la principal razón para impulsar el vínculo gobierno-migrante quienes como resultado del proceso de adaptación y la resiliencia demostrada por la población migrante de origen mexicano, el desarrollo de políticas de participación en la diáspora es un ejercicio político que solo ha ido ganando fuerza en los últimos 20 años. Los cambios constitucionales internos y el activismo político desde el exterior han impulsado a las sociedades de cooperación entre las instituciones y aquellos que desean ser incluidos en el juego político desde el exterior.

Dicho lo anterior, cabe resaltar que la relación entre el gobierno mexicano y su diáspora ha tenido varios contratiempos. Los años setenta vieron crecer un período nacionalista en ambos lados de la frontera de Estados Unidos y México. Los años ochenta trajeron un compromiso entre las dos partes que se basó en el desempeño de la economía mexicana. Dados los avances en materia de participación político-electoral, este capítulo analizará la evolución del compromiso que han adquirido los impulsores del proyecto democratizador de la política mexicana para que este incluya, y brinde atención especial, a la población migrante desde el punto de vista histórico oficial, así como desde la perspectiva de los migrantes.

Para ello, se hará un recuento histórico buscando contextualizar cómo es que se logró establecer el voto de los mexicanos desde el exterior, para pasar a analizar cuáles fueron algunas de las propuestas realizadas por el Legislativo, Ejecutivo, así como la sociedad civil. Como tercer apartado, se hará un recuento de los procesos electorales presidenciales en los que el voto de los mexicanos radicados en el exterior ha figurado, tal vez no como determinante de los resultados, pero sí como elemento de democratización e inclusión de aquellos que deseaban formar parte del proceso electoral mexicano. El objetivo de este trabajo es apuntalar, a 
través de la revisión de material histórico, los factores que detonaron el debate para implementar una modalidad de voto en elecciones presidenciales para mexicanos que radican fuera del territorio nacional. Esto con la intención de recalcar cómo surge y, qué significó para el desarrollo democrático en México. Es por ello que se propone un análisis transversal que entrelace sobre el fenómeno migratorio mexicano, las relaciones Estado-Diáspora y el empoderamiento de los clubes de migrantes en Estados Unidos.

\section{RECONOCIMIENTO Y REPRESENTACIÓN MIGRATORIA}

El fenómeno migrante mexicano es uno de ciclos; se mueve lentamente, de acuerdo con las personas en el poder y las circunstancias de su relación con los Estados Unidos. La protección oficial de la diáspora mexicana ha tenido varios episodios que se remontan a principios del siglo XX. Los primeros pasos hacia la inclusión política y electoral de los mexicanos residentes en el exterior surgen oficial y formalmente en las elecciones presidenciales de 1988 cuando el candidato Cuauhtémoc Cárdenas realizó una gira por Estados Unidos, visitando a las comunidades de mexicanos en Chicago y Los Ángeles para escuchar sus pesares como mexicanos. Previo a ello, hubo acercamientos entre el Estado y la Diáspora, pero no contemplaban la cooperación política, mucho menos el reconocimiento de los derechos otorgados y resguardados por la Constitución Política Mexicana.

Los primeros pasos hacia una reforma electoral democratizadora se dan en 1986 con el nacimiento del Código Federal Electoral en reemplazo de la Ley Federal de Organizaciones Políticas y Procesos Electorales ${ }^{1}$, aprobada en 1977. Este nuevo reglamento replantea muchos aspectos de los anteriores y se aplicó en las elecciones federales de 1988. Al interior de la política nacional, las demandas por la democratización comenzaron a surgir dentro del Partido Revolucionario Institucional (PRI), exigiendo una designación abierta del candidato presidencial, así como cambios en la dirección del gobierno y la política económica para defender el proyecto del nacionalismo revolucionario, oponiéndose a la aplicación de un proyecto económico que abriera la economía al libre comercio y las políticas neoliberales.

Al hacer caso omiso a las demandas en el seno del Partido, y fuera de este proceso, nació la Corriente Democrática del PRI, liderada por Cuauhtémoc Cárdenas y Porfirio Muñoz Ledo, entre otros. ${ }^{2}$ Después de no poder satisfacer sus demandas, mantener una postura nacionalista y evitar la incursión de tecnócratas en la escena política, la Corriente Democrática rompió con el partido y expresó abiertamente su interés en participar en la contienda electoral de 1988.

Por primera vez desde su fundación en la década de 1930, el PRI fue amenazado por el rango de apoyo que la oposición estaba recibiendo en el extranjero.

1 CHRISTIAN UZIEL GARCÍA REYES, "Los partidos políticos y las elecciones en México: del partido hegemónico a los gobiernos divididos”, Estudios Políticos, vol. 9, núm. 19, enero-abril, Universidad Nacional Autónoma de México, México, 2010, pp. 129-157.

2 RICARDO BECERRA, et al., La Mecánica Del Cambio Político. En México: Elecciones, Partidos y Reformas, México, Cal y Tierra, 2000, p. 201. 
Los conflictos internos del PRI permitieron que la oposición, principalmente el grupo de Cuauhtémoc Cárdenas, avanzara en las encuestas. A su vez, las elecciones presidenciales se volvieron más competitivas y el control del proceso por parte del gobierno se debilitó, dando lugar a un sistema electoral que creó progresivamente condiciones más equitativas para todos los partidos. ${ }^{3}$

Mientras tanto, en Estados Unidos, movilizaciones de las asociaciones de migrantes que favorecían al Frente Democrático Nacional y se oponían al candidato del PRI, Carlos Salinas de Gortari, comienzan a resonar en el ámbito nacional. Es así como las campañas presidenciales de 1988 adquirieron un toque internacional de interés. Cano y Délano ${ }^{4}$ afirman que, por primera vez los partidos mexicanos compitieron por la lealtad de los mexicanos y estadounidenses de origen mexicano en los Estados Unidos. Los mexicanos residentes en Estados Unidos fueron considerados como activos políticos del proceso electoral, como ciudadanos de México.

Este renovado interés en la comunidad migrante hizo que la relación con el gobierno mexicano fuera más dinámica. A lo largo de los años setenta y ochenta, su vínculo fue meramente mediante actividades consulares. Sin embargo, como consecuencia de los fenómenos electorales del ' 88 , los lazos con la comunidad chicana de primera, segunda y alta generación se fortalecieron a través de iniciativas informales de organización y de negocios, dado que el activismo transnacional del gobierno sentó las bases para el desarrollo de Respuesta integral a los problemas de migración en los años noventa. Conforme se acercaban las elecciones, más fuerte era el clamor por el derecho al voto de los mexicanos en el extranjero. La demanda comenzó a fortalecerse entre la población migrante mexicana teniendo a las asociaciones y federaciones de clubes de migrantes como maquinaria politizada por los candidatos de la oposición.

Con la llegada de Carlos Salinas de Gortari a la presidencia, México fue un país políticamente nuevo en muchos aspectos. Durante la administración de Salinas, la actividad consular estuvo en lo más alto de la lista de prioridades. Desde el otro lado de la frontera, la principal preocupación era lograr que el gobierno institucionalizara el movimiento de migrantes. A esta demanda, surgió la creación del Programa de las Comunidades Mexicanas en el Exterior (PCME), el Programa Paisano, las Oficinas Estatales de Atención a Migrantes (OFAMS) y los Grupos Beta de Protección a Migrantes. ${ }^{5}$ Estos programas se realizaron en los Ministerios de Relaciones Exteriores (SRE) y del Interior (SEGOB). La idea surgió del hecho de que el gobierno quería promover los lazos comerciales entre los mexicanos de ambos lados de la frontera. Los OFAMS fueron la primera instancia de asistencia y comunicación entre los inmigrantes y el gobierno del PRI.

3 PEDRO VALTIERRA, "El regreso del Rey del Tomate: Arturo Cano", La Jornada, México, julio de 2004, http://www.jornada.com.mx/2004/07/11/040f2con.html.

4 GUSTAVO CANO, y ALEXANDRA DÉLANO, "The Mexican Government and Organised Mexican Immigrants in The United States: A Historical Analysis of Political Transnationalism (1848-2005)", Journal of Ethnic and Migration Studies, vol. 33, núm. 5, 2007, pp. 695-725.

5 KATRINA BURGESS, "Collective Remittances and Migrant-State Collaboration in Mexico and El Salvador", Latin American Politics and Society, vol. 54, núm. 4, 2012, pp. 119-146. 
En el frente político participativo, se hicieron cambios constitucionales para modificar las leyes electorales, se estableció un nuevo registro electoral y los organismos de gestión electoral fueron ciudadanos para eliminar la falta de credibilidad de los partidos políticos, reducir las dudas sobre la transparencia de los procesos electorales y buscar la participación ciudadana en las elecciones. En 1990, las reformas electorales llevaron a la creación del Código Federal para Instituciones y Procedimientos Electorales (COFIPE) ${ }^{6}$ que incluía la extensión de los derechos de los partidos políticos y un nuevo mecanismo para la financiación del partido. También estipuló la creación del Instituto Federal Electoral (IFE), un nuevo censo electoral y una tarjeta de identificación de votante con fotografía. Estas últimas dos inclusiones al COFIPE fueron puntos contra la habilitación del voto ciudadano desde el extranjero.

Una nueva ronda de reformas en 1993 y 1994 incorporó observadores electorales nacionales e internacionales a los procesos electorales, lo que significó la adopción de un aparato legal internacional puesto en marcha para legitimar las elecciones presidenciales del 1994. ${ }^{7}$ Además, hubo modificaciones al artículo 82 de la Constitución que establecía que a partir de las elecciones del 2000 cualquier mexicano de nacimiento podría aspirar a la Presidencia eliminando la cláusula que demandaba el nacimiento de ambos padres hubiese ocurrido en suelo nacional. Con esta reforma, la posibilidad de tener candidatos con padre o madre naturalizado abría la posibilidad para que personas como Vicente Fox Quesada en 2000, pudieran competir e ingresar a la presidencia legal y legítimamente.

Las elecciones presidenciales de 1994 se convirtieron en un evento internacional con expectativas similares, como lo ocurrido en 1988. Una vez más, el candidato del PRD cruzó la frontera en busca de obtener el apoyo de los inmigrantes en ciudades focales como Los Ángeles y Chicago. Como demanda al gobierno nacional para incluir a la diáspora mexicana en actividades electorales, estos realizaron simulaciones electorales para replicar el mismo proceso que el ofrecido por el IFE en México.

Una vez llegado Ernesto Zedillo a la presidencia, las relaciones entre México y Estados Unidos adoptaron una postura más regionalizada. Ello como resultado a la campaña antiinmigrante plasmada en la Propuesta 187 (Prop 187) y promovida por el entonces gobernador de California, Pete Wilson, del Partido Republicano, que pretendía negar la educación y los derechos básicos de los inmigrantes indocumentados. ${ }^{8}$ La Prop 187 también significó el un estancamiento en las relaciones México-California y, a la par, dio lugar al surgimiento de un compromiso político transnacional por la comunidad mexicana. Desde otra

6 CHRISTIAN UZIEL GARCÍA REYES, "Los partidos políticos y las elecciones en México: del partido hegemónico a los gobiernos divididos", Estudios Políticos, vol. 9, núm. 19, enero-abril, Universidad Nacional Autónoma de México, México, 2010, pp. 129-157.

7 REYNALDO ORTEGA ORTÍZ y MA. FERNANDA SOMUANO, Confianza y Cambio Político En México: Contiendas Electorales y El IFE, México, El Colegio de México, 2012, p. 79.

8 DAVID R. AYÓN, "La Política Mexicana y La movilización de los migrantes mexicanos en Estados Unidos", en CARLOS GONZÁLEZ GUTIÉRREZ, Relaciones Estado-Diáspora: Perspectivas de América Latina y El Caribe, México, Miguel Ángel Porrúa, 2006, p. 138. 
perspectiva, México necesitaba reaccionar en defensa de su población inmigrante a través de medios diplomáticos. Por otro lado, los líderes políticos latinos en California comenzaron a instar a los inmigrantes a continuar y concluir su proceso de naturalización u obtención de la ciudadanía y poder votar en las elecciones estatales próximas.

El gobierno de Zedillo entendió que necesitaba restablecer un vínculo con la diáspora mexicana que vive en California y que trabaja con los líderes del Congreso estatal para promover la adopción de la ciudadanía estadounidense. Desde la perspectiva de California, los líderes latinos, especialmente los más cercanos al candidato a gobernador, Gray Davis, se dieron cuenta del impacto negativo que el paquete de reforma de inmigración promovido por el gobierno de Pete Wilson conllevó. Zedillo pudo restablecer las relaciones con el gobierno de California una vez que Gray Davis fue elegido gobernador en 1998. Ese vínculo que se formó en el transcurso de la administración de Zedillo facilitó la transición cuando Vicente Fox llegó al poder en 2000.

La primera visita oficial del gobernador Davis fue a México. Este viaje, que fue una invitación del gobierno mexicano, fue representativo del vínculo que existía entre la administración federal mexicana y fue el funcionario electo más alto en visitar México en ese momento. Davis viajó a México anteriormente mientras era teniente gobernador; Pete Wilson no tenía los mismos respetos con respecto a México y sus lazos económicos, por lo que para la administración recién elegida de California ir a México significaba mantener abierto ese puente de comunicación. ${ }^{9}$ Desde el lado mexicano, mantener relaciones estables con estados como Texas, Illinois y California también representaban un paso hacia el fortalecimiento de las relaciones con la diáspora mexicana, al considerar este un programa de acercamiento con la comunidad de inmigrantes.

La llegada de Vicente Fox a la presidencia facilitó la implementación de programas pro-migrante, así como la creación de agencias que atendían a la Diáspora, especialmente en los Estados Unidos. El primer éxito de la administración del PAN llegó cuando la Oficina Presidencial para los Mexicanos en el Exterior (OPME) comenzó a operar con el objetivo de promover inversiones productivas entre la comunidad mexicana en los Estados Unidos. Además, durante la administración de Fox surge el Consejo Nacional de Oficinas de Atención al Migrante o CONOFAMS. ${ }^{10}$ Su tarea principal era coordinar las tareas de las oficinas estatales de atención a los migrantes desde una posición centralizada.

Aunado a estos avances en materia migratoria, la administración de Fox presentó una iniciativa para reformar la ley electoral y permitir que la comunidad mexicana que vive en el extranjero vote por el presidente de México. Este esfuerzo

9 GUSTAVO CANO, y ALEXANDRA DÉLANO, "The Mexican Government and Organised Mexican Immigrants in The United States: A Historical Analysis of Political Transnationalism (1848-2005)", Journal of Ethnic and Migration Studies, vol. 33, núm. 5, 2007, p. 723.

10 GUSTAVO CANO, y ALEXANDRA DÉLANO, "The Mexican Government and Organised Mexican Immigrants in The United States: A Historical Analysis of Political Transnationalism (1848-2005)", Journal of Ethnic and Migration Studies, vol. 33, núm. 5, 2007, p. 714. 
comenzó en 1996 y fue examinado por el organismo de gestión electoral en 1998, pero fue Vicente Fox, con el apoyo del Congreso, quien aprobó la medida en 2005. Por primera vez los ciudadanos mexicanos tendrían la capacidad para votar por el presidente de los Estados Unidos de México mientras vivían en el extranjero.

\section{EVOLUCIÓN Y DEBATE DE LA LEY ELECTORAL}

En 1998 se publicó el "Informe final de la Comisión de Especialistas que estudia las modalidades del Voto de los mexicanos en el extranjero" que planteaba el voto a través de varias modalidades; casillas ordinarias, casillas especiales y el voto a distancia (por correo postal o telefónicamente). Para poder implementar el voto presencial, casillas ordinarias o especiales, sería un tecnicismo, de acuerdo al Informe ya que solo requería ciertas adecuaciones logísticas dado que la legislación electoral contaba con referencias claras sobre el tema. La tercera modalidad, al ser virtual, implica un procedimiento novedoso". ${ }^{11}$

El reporte concluyó que cada modalidad planteada, de registro y ejecución del voto, no contaba con un conteo exacto del núcleo total de electores que viven en el extranjero. Inicialmente se buscaría atender un estimado de 10.8 millones de ciudadanos mexicanos en el 2000, del cual el 99 por ciento de ellos radicaba en Estados Unidos. ${ }^{12}$ La Comisión de Especialistas no consideró que fuera relevante el tiempo de residencia en el exterior como condición para el registro en el padrón electoral especial y, por esa razón, se establecieron como únicas condicionantes tener la nacionalidad mexicana y la mayoría de edad de acuerdo a los lineamientos mexicanos.

Además, el informe hizo una serie de sugerencias sobre cuál debía ser el procedimiento electoral a seguir si querían implementar el voto de los mexicanos residentes en el extranjero para el año 2000. Los puntos clave resaltados por la Comisión de Especialistas que estudia las modalidades del voto de los mexicanos en el extranjero resaltan la aplicación de nuevas tecnologías para la verificación de identidades e información que garanticen y conserven la seguridad durante la elaboración del padrón electoral; efectuar estudios demográficos que generen patrones de dispersión y concentración de los mexicanos en el exterior; incluir en el Código Electoral nuevas modalidades para recabar y escrutar el cómputo y escrutinio de los votos; considerar el papel de los partidos políticos, en especial la recaudación de recursos desde el extranjero y; habilitar el acceso a la información relativa a las plataformas de campaña y candidatos presidenciales de los distintos partidos. ${ }^{13}$

De aquí surgieron varios proyectos no sólo para reformar la Constitución sino también para cambiar e incluso agregar estatutos al Código Federal de Instituciones

\footnotetext{
11 Instituto Federal Electoral, Informe Final de la Comisión de Especialistas que estudia las modalidades del Voto de los Mexicanos en el Extranjero, IFE, México, p. 4.

12 Instituto Federal Electoral, Informe Final de la Comisión de Especialistas que estudia las modalidades del Voto de los Mexicanos en el Extranjero, IFE, México, p. 6.

13 Instituto Federal Electoral, Informe Final de la Comisión de Especialistas que estudia las modalidades del Voto de los Mexicanos en el Extranjero, IFE, México, p. 26-48.
} 
y Procedimientos Electorales. Entre 1998 y 2003, fueron presentadas 14 iniciativas $^{14}$ para modificar la legislación electoral. Aunado a los proyectos, se dio una gran discusión entre intelectuales, técnicos y especialistas que se situaban a favor o en contra del voto en el extranjero. Los principales analistas del tema vinieron de la Cámara de Diputados y del IFE.

Además de lo realizado por investigadores y especialistas, a principios del 2004, una consultoría particular realizó un estudio sobre la viabilidad del voto en el extranjero. Ésta expuso las características de los ciudadanos y del proceso; sus ventajas y desventajas; el objetivo y fines de la reforma ${ }^{15} \mathrm{y}$; las posiciones de los partidos Acción Nacional, Revolucionario Institucional y de la Revolución Democrática. Al final de dicho reporte, se hizo un análisis de riesgo describiendo lo que podría ocurrir si no se llevasen a cabo las reformas constitucionales y al COFIPE.

La primera de las iniciativas se presentó en junio del 2004 en la Cámara de Diputados por el entonces Presidente Vicente Fox Quesada. El Proyecto de decreto, que reforma y adiciona diversos artículos del COFIPE ${ }^{16}$ resalta la demanda para hacer efectivos los derechos de voto desde el extranjero a partir de la elección presidencial del 2006; garantizar la seguridad, privacidad y limpieza electoral; condonación y castigar actos públicos de campaña fuera del territorio nacional por los partidos políticos y sus candidatos; elaborar una Lista Nominal de Electores en el Extranjero y; establecer una Junta Ejecutiva para el Voto de los Mexicanos en el Extranjero, responsable de la instrumentación del proceso electoral en el extranjero. ${ }^{17}$

En general las propuestas de ley buscaban la inclusión de los mexicanos a su manera. La propuesta de Fox, así como las otras no tenían un plan concreto de cómo debía hacerse. Enfatizaban establecer una estructura similar a la que existe para realizar el proceso electoral al interior de México. Los partidos políticos compartían la idea que vivir fuera de México no debía descalificar ni anular los derechos de representación protegidos por la Constitución y el Código Federal Electoral.

Para julio de 2004, el CESOP de la Cámara de Diputados realizó un análisis sobre el voto en el extranjero. Dicho análisis planteaba los diferentes aspectos a deliberar, desde lo conceptual, el marco jurídico y los desafíos logísticos para la instrumentación, proporcionando cifras del posible electorado en el exterior y

\footnotetext{
14 MIGUEL MOCTEZUMA, "Coyuntura y debate: Viabilidad del voto extraterritorial de los mexicanos", $M i$ gración y Desarrollo, núm. 2, 2004, pp. 107-119.

15 ROBERTO SURO y GABRIEL ESCOBAR, Survey of Mexicans Living in the U.S. on Absentee Voting in Mexican Elections, Pew Hispanic Center, 2006, pp. 3-5.

16 Ver la Gaceta Parlamentaria de la H. Cámara de Diputados, número 1522, 18 de junio de 2004.

17 VICENTE FOX QUESADA, "Iniciativa con proyecto de decreto que reforma y adiciona diversos artículos del Código Federal de Instituciones y Procedimientos Electorales para hacer efectivo el derecho al voto de los ciudadanos mexicanos que se encuentren en el extranjero", en JUAN JOSÉ GARCÍA OCHOA, Derechos políticos plenos para los mexicanos en el exterior, Grupo Parlamentario del PRD en la LIX Legislatura de la Cámara de Diputados del Congreso de la Unión, México, 2004, pp. 173-189.
} 
presentando los principales argumentos a favor y en contra del voto en el extranjero. ${ }^{18}$ Una de las manifestaciones trascendentales en contra se centraba en la cuestión de lealtad de la Diáspora, y la probabilidad que se pierdan los lazos de relación.

La discusión en torno a la polarización del arraigo y lealtad a la mexicanidad no prosperó debido a esa costumbre tan arraigada en México de politizar los problemas y fenómenos sociales. ${ }^{19} \mathrm{El}$ principal obstáculo para oficializar el voto extraterritorial era la politización del mismo. Los gobiernos priístas consideraban que los mexicanos residentes en el extranjero optarían por las otras opciones partidistas. Los partidos de oposición estimaban que el voto desde el exterior se inclinaría por una transición del poder en las elecciones presidenciales. Otro punto de discordia sobre qué facultades de carácter electoral, si es que alguna, debía otorgar la ley electoral a los trabajadores del Servicio Exterior Mexicano para promover el voto en casillas especiales.

Con la división de posturas, surgieron varias razones para que el voto se contemplara cuidadosamente y no se buscase una solución simplista. Primero, debía analizarse cuál sería la instrumentación del voto en el exterior, los costos y estructuras, y después, considerarse las modalidades de registro y emisión del voto. ${ }^{20}$ El marco legal era otro tópico de discusión y también lo era el respeto de los derechos de los migrantes y no sólo sus derechos políticos. Conjuntamente, esta agenda de protección de los migrantes debería atender las demás preocupaciones desatendidas como la tenencia de papeles legales, programas de protección, programas de orientación, en fin, una larga lista.

\section{ELEGIBILIDAD AL VOTO EN EL EXTERIOR}

Esta discusión no era nueva durante el periodo de escrutinio de las propuestas del voto extraterritorial sino desde fines de los ochenta. El hecho de realizar un debate, con formato de foro nacional o comisionar especialistas del tema para analizar estos puntos era urgente y necesario. Las propuestas expuestas llegaron a centrarse en otorgar el derecho al voto; modo de registro; método de emisión del voto; y las campañas políticas fuera del territorio. Cada posición política partidista tenía su postura en cada tema; a veces concordaron, a veces no, sin embargo, fue el IFE el encargado del análisis de viabilidad para el proceso electoral fuera de México. Las iniciativas de reforma defendían la idea de retomar el derecho otorgado por la Constitución a todos los ciudadanos mexicanos. Ejemplo de ello fue la discusión sobre la viabilidad del Artículo 35, analizado y casi destrozado en un intento por mostrar la constitucionalidad de permitir a ciudadanos

18 JORGE CARPIZO, y DIEGO VALADÉS, El Voto de los Mexicanos en el Extranjero, Instituto de investigaciones Jurídicas, segunda edición, México 1999, p. 6.

19 VÍCTOR ESPINOZA VALLE, El voto lejano: Cultura política y migración México-Estados Unidos, El Colegio de la Frontera Norte y la Editorial Miguel Ángel Porrúa, México, 2004, p. 30.

20 JORGE SANTIBÁÑEZ ROMELLÓN, "Migrantes mexicanos en los estados unidos, su número y su voto en las elecciones de México", en JUAN JOSÉ GARCÍA OCHOA (coord.), Derechos políticos plenos para los mexicanos en el exterior, Grupo Parlamentario del PRD en la LIX Legislatura de la Cámara de Diputados del Congreso de la Unión, México, 2004, p. 30. 
mexicanos llevar a cabo sus prerrogativas legales desde afuera del país. El COFIPE, ${ }^{21}$ en específico su Artículo 6, al igual que la Constitución, tampoco mostraba ninguna inconformidad con dar visto bueno al voto desde el extranjero.

El primer punto resalta el respeto de los derechos de los migrantes como un grupo influyente en el ámbito nacional. La Diáspora dejaba de figurar como simples contribuyentes de remesas para convertirse en actores políticos acreditados por las leyes mexicanas para tomar decisiones políticas que los afectarían directamente, así como al resto de la población en México.

En lo referente a la identificación de los residentes en el extranjero como electores, existió una polémica debido a la falta de consenso para crear un Padrón Electoral de los mexicanos en el extranjero y; la incorporación de aquellos cuyas credenciales de elector seguían vigentes. Por otro lado, se barajeaba la idea de desechar el Padrón Electoral existente y crear una Lista Nominal de Electores en el Extranjero.

Otro punto de reflexión resultó ser la instalación de casillas especiales. Estas se planteaban como posibilidades reales y su instalación se daría a lo largo de la frontera, en centros turísticos con alta afluencia de mexicanos y en aeropuertos, puertos marinos o instalaciones gubernamentales. Para poder votar, estos deberían presentar algún documento de identidad que los identificasen como mexicanos.

Una ventaja que se veía con la inclusión de los mexicanos en el extranjero al padrón rondaba sobre el hecho que se tendría una cifra oficial del total de la Diáspora. Por otro lado, desde una perspectiva de la defensa de los migrantes indocumentados, resultaría un peligro latente. ${ }^{22} \mathrm{El}$ gobierno mexicano tendría información respecto a la residencia de sus ciudadanos en el extranjero, sin importar su situación legal. Sin embargo, los mexicanos irregulares rechazarían esta noción por temor que el gobierno estadounidense exigiera al mexicano a compartir esta información para efecto de detección y deportación.

Después de la batalla por definir la modalidad de registro, se buscaba establecer la manera ideal de voto. La instalación de casillas en zonas fronterizas era una de las propuestas con mayor atención. La primera desventaja de esta viabilidad era la exclusión de los migrantes mexicanos que viviesen alejados de los límites territorial entre México y Estados Unidos y México-Belice y México-Guatemala en la zona sur del país, así como países que no comparten frontera con México. Las casillas en lugares turísticos con un alto índice de mexicanos tampoco eran viables ya que también dejaba fuera a una mayoría de población con derecho al voto. Además, el voto a través de casillas especiales en polos turísticos resultaba en un proceso excluyente de aquellos que no cuentan con los recursos para desplazarse por diversión y descanso.

El voto a distancia, postal, telefónico y/o electrónico, igual mostraba ciertas limitantes a la seguridad y legitimidad del proceso electoral. El problema con estas

21 Código Federal de Instituciones y Procedimientos Electorales, 2009, México, p. 2.

22 YURI BELTRÁN MIRANDA, “El Voto de Los Mexicanos Residentes En El Extranjero," en LUIS CARLOS UGALDE y SAID HERNÁNDEZ QUINTANA (coords.), Fortalezas y Debilidades Del Sistema Electoral Mexicano, México, Tribunal Electoral del Poder Judicial de la Federación, 2016, pp. 464-467. 
vías era la inmersión de intereses ajenos al proceso, así como la intrusión de hackers que alteraran, manipularan o secuestraran los resultados de las elecciones. ${ }^{23}$

Por último, se discutía la promoción y campañas de los partidos y candidatos en el exterior. Las propuestas de los perredistas, panistas y del presidente Fox se oponían a que los partidos políticos o candidatos realizaran actos de proselitismo y promoción, invirtieran en promoción o recibieran financiamiento o estímulos económicos, o propagandista, proveniente del exterior de México. Dichas tareas y obligaciones son propias del organismo de gestión electoral nacional.

Por su parte, el PRI apoyaba la idea de facilitar el proselitismo en, y desde, el extranjero. Robert Suro y Gabriel Escobar realizaron una encuesta a principios del 2006 que mostraba la baja popularidad y aprobación del PRI. ${ }^{24}$ La información recabada presentaba que, de 987 personas encuestadas, 36 por ciento estaban registrados en el padrón electoral de México y afirmó inclinarse por el PAN, y tan sólo un 14 por ciento por el PRI y PRD respectivamente. Del 36\% restante, un 34 dijo no tener inclinación política en México, 1\% no sabía al respecto y el porcentaje restante se rehusó a responder. La posibilidad de promover las candidaturas del Revolucionario Institucional en el exterior, se buscaría recortar la distancia en preferencias electoral y niveles de aprobación del Acción Nacional.

Después de los trabajos de debate y de las reuniones de consulta, en la sesión ordinaria del 27 de abril de 2005, los senadores le dieron el visto bueno a la minuta con la adición de un Libro Sexto al COFIPE intitulado "Del Voto de los Mexicanos Residentes en el Extranjero", adoptando la modalidad de voto postal con una votación de 91 votos a favor, 2 en contra y 1 abstención. ${ }^{25}$

\section{CAMBIOS A LA LEY ELECTORAL}

La discusión legislativa por fin quedó concluida en la sesión de la Cámara de Diputados el 28 de junio de 2005, con la aprobación de la iniciativa previamente certificada en la Cámara de Senadores, con 455 votos a favor del proyecto, 6 en contra y 6 abstenciones. En las votaciones que se realizaron en el Congreso de la Unión, los legisladores se manifestaron a favor del voto en el extranjero con una aceptación alta. ${ }^{26}$ Las reformas adicionaron los Artículos 273 al 300 para crear el Libro Sexto, Del Voto de los Mexicanos en el Extranjero. ${ }^{27}$ Los Art. 273 al 275 resaltan los derechos de los mexicanos en el exterior. Los Artículos 276 al 282

23 Este fue un tema que buscó solucionar el gobierno mexicano y el Instituto Nacional Electoral posterior a la reforma que transformo al COFIPE en el LEGIPE en 2014. Después de las elecciones presidenciales del 2012, el IFE retomó las posibilidades de emitir el voto extraterritorial electrónicamente, por lo que se buscaron medios que hicieran esto una posibilidad.

24 ROBERTO SURO y GABRIEL ESCOBAR, Survey of Mexicans Living in the U.S. on Absentee Voting in Mexican Elections, Pew Hispanic Center, 2006, p. 16.

25 Para tener una descripción mejor detallada, véase la Gaceta Parlamentaria, Cámara de Diputados, número 1785-III, martes 21 de diciembre de 2005.

26 Cabe resaltar que el Código al que se refiere este apartado, es el aceptado en 2005. A partir de ese año ha sido modificado y en los procesos de reforma dejó de ser un Código para convertirse en Legislación en 2015.

27 VÍCTOR ALEJANDRO ESPINOZA VALLE, El voto lejano: Cultura politica y migración México-Estados Unidos, El Colegio de la Frontera Norte y la Editorial Miguel Ángel Porrúa, México, 2004, p. 25. 
detallan las cuestiones de registro y control en las listas nominales de electores en el extranjero. Los Artículos 283 al 295 escrudiñan la impresión de las boletas y sobres que se enviarían al exterior, así como el procedimiento para la recepción de los paquetes y el conteo de los votos postales.

Los artículos 296 y 297 resaltan las cuestiones de financiamiento y proselitismo referido en el Artículo 182 y el 182-A ${ }^{28}$ del mismo reglamento. ${ }^{29}$ El Art. 296 establece la prohibición a llevar a cabo actividades, actos y propaganda electoral en el extranjero los partidos políticos mexicanos y sus candidatos. De acuerdo al Art. 182, por campaña electoral, debe entenderse todo acto que promueva o intente al voto, a través de reuniones públicas, asambleas, y marchas. También prohíbe la distribución de escritos, publicaciones, imágenes, grabaciones u otro material impreso o audiovisual que exprese y difunde favoritismo hacia los partidos políticos nacionales y los candidatos.

El Art. 296 también limita la entrada de recursos y financiamiento que estimule e impulse la campaña electoral de candidatos y los partidos políticos. En este apartado es importante de resaltar que la ley alude al financiamiento lo que deriva en qué puede y debe entenderse como financiamiento, ya sea público o privado, por ejemplo, además de considerar el origen del mismo. Este artículo interpone la necesidad de limitar la entrada y salida de recursos que promuevan proselitismo durante el periodo de campaña electoral. El dinero proviene del órgano de gestión electoral, limitando donaciones desde el interior o exterior de México. Por otro lado, también ratifica que es una falta al Código y sancionable recibir financiamiento para promover la imagen de los candidatos en el exterior. El Artículo 49, Fracción 2, indica que los partidos políticos no podrán recibir financiación bajo ninguna circunstancia por parte de organizaciones internacionales, partidos políticos extranjeros o personas físicas o morales extranjeras, ni de personas que vivan o trabajen en el extranjero. El COFIPE ${ }^{30}$ buscaba blindar al proceso electoral y ofrecer un sentido de transparencia a la vez en cuanto al financiamiento ilícito o indebido en, y desde, el exterior de México durante el periodo electoral.

Por su parte, el Artículo 297 indica el procedimiento para denunciar y desahogar las quejas a las violaciones del artículo anterior. En caso de existir alguna disputa por violaciones al Art. 296, concerniente a la financiación electoral, podrá ser denunciada ante el Secretario Ejecutivo del Instituto. Es deber de los representantes de los partidos políticos llevar a cabo la contestación ante el Consejo General para desahogar las quejas, especialmente en temas de financiamiento. Los Artículos 49-A y 49-B sirven como base para realizar la denuncia por violaciones al Código electoral. Estipulan que los partidos deben presentar los informes anuales de ingresos, incluyendo el origen y monto destinado por cualquier modalidad; de

\footnotetext{
28 Estos Artículos aluden a las limitaciones y permisiones durante la campaña electoral, así como topes para los actos de gastos que realicen los partidos políticos, las coaliciones y sus candidatos, en la propaganda electoral y las actividades de campaña.

30 Código Federal de Instituciones y Procedimientos Electorales, 2009, México, p. 18.
} 
campaña, especificando los gastos del partido y candidato en el ámbito territorial, de acuerdo a lo establecido en el Art. 182-A. Además, las quejas sobre el origen y la aplicación de los recursos derivados del financiamiento político deberían turnarse ante el Secretario Ejecutivo del Instituto Federal Electoral para analizar y efectuar el dictamen al respecto.

En este apartado es importante resaltar que el presupuesto del IFE para el ejercicio del voto en el extranjero no entra en estos apartados dado que será el órgano encargado del manejo de la elección (Artículo 299). Por su parte, los Artículos 298 y 300 resaltan la necesidad de elegir un Consejo General con un año de antelación a la elección presidencial, así como la creación de unidades administrativas de apoyo para cubrir las tareas del proceso electoral. Será este Consejo el encargado de hacer respetar este Código.

\section{COSTOS Y BENEFICIOS DE ACCESIBILIDAD}

El proceder del voto desde el exterior resultaba costoso y se cuestionaba su aportación al desarrollo democrático en México. A pesar de ello, en agosto de 2005, el IFE aprobó un presupuesto para la contienda presidencial de $\$ 12,920.60$ millones de pesos. Después de una revisión por la Cámara de Diputados, la valoración de las elecciones presidenciales del 2006 quedó fijada en $\$ 11,892.10$ millones de pesos, con un gasto operativo de 6,842.90 millones de pesos y; 265.90 millones de pesos para el voto desde el exterior. Ésta fue una suma muy significativa ya que $2.24 \%$ del presupuesto aprobado para el ejercicio electoral se destinó para la práctica del voto en el exterior de México. Este monto, además, representa un 25 por ciento de los $\$ 1,062$ millones de pesos solicitados para este ejercicio. ${ }^{31} \mathrm{Al}$ ser la primera experimentación con el voto lejano para mexicanos no existía precedente económico que fungiera como base.

El presupuesto del IFE tiene como prioridad cubrir tres rubros principales del voto en el extranjero, financiamiento para el envío y recepción de la documentación electoral; gasto de operación de la Coordinación del Voto de los Mexicanos Residentes en el Extranjero (COVE) y; difusión del voto en el extranjero. ${ }^{32}$ Se administraron 42.80 millones de pesos para asegurar el envío y recepción de los paquetes electorales y las boletas para la elección. Los costos de operatividad de la COVE ascendieron a 36.57 millones de pesos. Con ello se dio prioridad a los proyectos vinculados con el proceso electoral federal. Por último, $185.91 \mathrm{mi}$ llones de pesos a los que disponía el IFE, 36 millones $^{33}$ fueron asignados y aprobados por el Consejo General del Instituto para realizar una fuerte campaña promocional televisiva, por radio, medios impresos, e Internet involucrando a

31 YURI BELTRÁN MIRANDA, “El Voto de Los Mexicanos Residentes En El Extranjero,” en LUIS CARLOS UGALDE y SAID HERNÁNDEZ QUINTANA (coords.), Fortalezas y Debilidades Del Sistema Electoral Mexicano, México, Tribunal Electoral del Poder Judicial de la Federación, 2016, p. 481.

32 IFE, Informe Final del Voto de los Mexicanos Residentes en el Extranjero. Proceso Electoral Federal 20112012, México, 2013, p. 4.

33 REYNALDO ORTEGA ORTÍZ y MA. FERNANDA SOMUANO, Confianza y Cambio Político En México: Contiendas Electorales y El IFE, México, El Colegio de México, 2012, p. 80. 
mexicanos destacados en su medio profesional. La repartición del monto total otorgado, entonces fue redistribuida como se muestra en la siguiente tabla. El resto de recurso se destinó a la instalación de módulos informativos especiales, al monitoreo de los mensajes electorales por las instituciones, la orientación respecto al voto extraterritorial y otros servicios. Al finalizar el proceso electoral, el IFE hizo un reembolso de más de 80 millones de pesos por falta de uso y para cumplir con la norma de transparencia órgano electoral.

Esta campaña consideró la promoción del voto utilizando los tiempos oficiales disponibles en medios de comunicación masiva en México, con el objeto de dar a conocer este derecho entre las familias y amistades de los migrantes y generar con ello la participación de los connacionales que residen en el exterior. Adicionalmente, se produjeron casetes y discos compactos con los mensajes de promoción del voto en el extranjero para ser transmitidos mediante el sistema de perifoneo en regiones del país donde hay mayor concentración de migración o de tránsito. Se produjeron 15 spots para la televisión y 11 para la radio. ${ }^{34}$ Se contrataron espacios en cadenas de televisión y de radio que pusieron en marcha espacios de información e intermediación entre los mexicanos y el IFE, sin costo para el Instituto. Para potenciar esta medida y multiplicar el mensaje de promoción del voto, se involucró a una serie de personalidades de la cultura popular y el deporte con gran aceptación en Estados Unidos. Asimismo, se implementó una campaña en medios impresos editados en español tomando en cuenta datos demográficos sobre la concentración de mexicanos y el tiraje de los diarios.

El gasto principal se implementó en la repartición de los Paquetes Electorales Postales. ${ }^{35}$ Los paquetes electorales se solicitaron directamente con el IFE. Lo único que los interesados debían hacer era comprobar ante los representantes electorales que tenían un domicilio fijo enviando una copia de su contrato de arrendamiento o de un recibo ya fuera de electricidad, agua, teléfono, o cualquiera que mostrara su permanencia en un sitio. Para quienes cumplieron con los requisitos, el IFE envió PEP, en tiempo y forma, de acuerdo a su inscripción en la Lista Nominal de Electores Residentes en el Extranjero (LNERE). El IFE comenzó con envío de los paquetes vía correo certificado el 21 de abril de 2006 y finalizó el 20 de mayo.

\section{CONCLUSIONES}

La implementación del voto de los mexicanos desde el exterior fue un trabajo perpetrado por el Instituto Federal Electoral y el INE después de su fundación. Sin embargo, esta modalidad del sufragio requirió la colaboración del sector público, privado y la sociedad civil nacional y transnacional. Los avances en materia electoral tienen su nacimiento en la política migratoria impulsada por

\footnotetext{
34 Instituto Electoral Federal, "Elecciones Federales 2006. Voto de los mexicanos residentes en el extranjero", Elecciones Federales 2006, México, p. 16.

35 Instituto Electoral Federal, "Elecciones Federales 2006. Voto de los mexicanos residentes en el extranjero", Elecciones Federales 2006, México, p. 23.
} 
las administraciones federales a partir de la década de los ochenta, que toma forma y fuerza durante los noventa para formalizarse entrando el nuevo siglo. Ante dicha postura de puertas abiertas por el gobierno federal es que la Diáspora mexicana adquiere relevancia en actividad política transnacional, con importancia al interior y en el exterior de México.

Actualmente hay miles de estas asociaciones, entre clubes de migrantes y federaciones de clubes de migrantes, en Estados Unidos y el resto del mundo. La formación constante de nuevas asociaciones y la inclusión de estos grupos en los registros del Instituto de Mexicanos en el Exterior y la Secretaría de Relaciones Exteriores es una clara señal de que el gobierno mexicano reconoce el interés de estos grupos por permanecer vinculados a México. A su vez, es una señal que el gobierno mexicano tiene interés por mantener a la Diáspora mexicana comprometida e interesada con el acontecer nacional. Con la aprobación de los lineamientos generales del voto postal por parte del IFE, el 21 de septiembre de 2005, señaló la intención por parte del Instituto en esclarecer y fortalecer la equidad y legalidad del proceso de manera transnacional.

Es por ello que las autoridades mexicanas buscaron los puntos débiles del proceso electoral a través del servicio postal para solucionarlos y efectuar el voto postal de manera eficiente y efectiva. Los principales retos a enfrentar seguían siendo la prohibición de financiamiento en todas sus modalidades que tuvieran el fin de gestionar el voto en el exterior; actos de campaña por los partidos y candidatos de manera independiente del Instituto y; la resolución de conflictos electorales, en especial en cuestiones de financiamiento indebido. Estos continúan siendo preocupaciones que sigue enfrentando el Instituto Nacional Electoral a la fecha.

\section{REFERENCIAS}

AYÓN, David, "La Política Mexicana y La movilización de los migrantes mexicanos en Estados Unidos", en GONZÁLEZ GUTIÉRREZ, Carlos, Relaciones Estado-Diáspora: Perspectivas de América Latina y El Caribe, México, Miguel Ángel Porrúa, 2006.

BECERRA, Ricardo; SALAZAR, Pedro y WOLDENBERG, José, La mecánica del cambio político en México: Elecciones, partidos y reformas, México, Cal y Tierra, 2000.

BELTRÁN MIRANDA, Yuri, "El Voto de Los Mexicanos Residentes En El Extranjero," en Ugalde, Luis Carlos y Hernández Quintana, Said (coords.), Fortalezas y Debilidades Del Sistema Electoral Mexicano, México, Tribunal Electoral del Poder Judicial de la Federación, 2016.

BURGESS, Katrina, "Collective Remittances and Migrant-State Collaboration in Mexico and El Salvador", en Latin American Politics and Society, vol. 54, núm. 4, 2012.

CANO, Gustavo y DÉLANO, Alexandra, "The Mexican Government and Organised Mexican Immigrants in The United States: A Historical Analysis of Political Transnationalism (1848-2005)", en Journal of Ethnic and Migration Studies, núm. 33, 2007. 
CARPIZO, Jorge y VALADÉS, Diego, El voto de los mexicanos en el extranjero, Ciudad de México, El Colegio de México, 2004.

Centro de Estudios Sobre la Opinión Pública, El voto de los mexicanos en el extranjero, 2004, disponible en: http://webcache.googleusercontent.com/ search?q=cache:_Vmo-vEVnqoJ:www3.diputados.gob.mx/camara/content/ download/21151/104976/file/FATSM005 El voto de los mexicanos en el extranjero.pdf $\& \mathrm{~cd}=1 \& \mathrm{hl}=\mathrm{es} \& \mathrm{ct}=\mathrm{clnk} \& \mathrm{gl}=\mathrm{mx}$.

DÉLANO, Alexandra, "De la "no intervención” a la institucionalización: la evolución de las relaciones Estado-diáspora en el caso mexicano, Relaciones Estado-Diáspora: Aproximaciones Desde Cuatro Continentes”, vol. 2, México, 2006.

Instituto Federal Electoral, Informe Final de la Comisión de Especialistas que estudia las modalidades del Voto de los Mexicanos en el Extranjero, México, 1998.

, Código Federal de instituciones y procedimientos electorales: Y otros ordenamientos electorales (4 ed.), México, 2005.

, "Comisiones Unidas de Gobernación y de Población, Fronteras y Asuntos Migratorios", La obra legislativa de la LIX Legislatura, Segundo Año de Ejercicio, 1 de septiembre de 2004 al 28 de abril de 2005.

, Gaceta Parlamentaria, Cámara de Diputados, número 1785-III, martes 21 de diciembre de 2005, México.

, "Elecciones Federales 2006. Voto de los mexicanos residentes en el extranjero", Elecciones Federales 2006, México.

ESPINOZA VALLE, Víctor Alejandro, 2004, El voto lejano: Cultura política y migración México-Estados Unidos, El Colegio de la Frontera Norte y la Editorial Miguel Ángel Porrúa, México.

, "Democracia y participación política a distancia. El voto de los mexicanos en el extranjero", Cuadernos de divulgación de la justicia electoral, Ciudad de México, 2013.

FITZGERALD, David, Rethinking emigrant citizenship, Estados Unidos, New York University Law Review, 2006.

FOX QUESADA, Vicente, "Iniciativa con proyecto de decreto que reforma y adiciona diversos artículos del Código Federal de Instituciones y Procedimientos Electorales para hacer efectivo el derecho al voto de los ciudadanos mexicanos que se encuentren en el extranjero", en García Ochoa, Juan José, Derechos políticos plenos para los mexicanos en el exterior, Ciudad de México, Grupo Parlamentario del PRD en la LIX Legislatura de la Cámara de Diputados del Congreso de la Unión, 2004.

MOCTEZUMA, Miguel, "Coyuntura y Debate: Viabilidad Del Voto Extraterritorial de Los Mexicanos", en Migración y Desarrollo núm. 2, México, 2004.

ORTEGA ORTÍZ, Reynaldo, y SOMUANO, Ma. Fernanda, Confianza y Cambio Político En México: Contiendas Electorales y El IFE, El Colegio de México, México, 2016. 
SANTIBÁÑEZ ROMELLÓN, Jorge, "Migrantes mexicanos en los estados unidos, su número y su voto en las elecciones de México", en García Ochoa, Juan José (coord.), Derechos políticos plenos para los mexicanos en el exterior, Grupo Parlamentario del PRD en la LIX Legislatura de la Cámara de Diputados del Congreso de la Unión, México, 2004.

SURO, Roberto, y ESCOBAR, Gabriel, Survey of Mexicans Living in the U.S. on Absentee Voting in Mexican Elections, Washington, DC, Pew Hispanic Center, Estados Unidos, 2006.

VALTIERRA, Pedro, "El regreso del Rey del Tomate: Arturo Cano", en La Jornada, México, 2004, disponible en http://www.jornada.com.mx/2004/07/ 11/040f2con.html. 